\title{
WEB-BASED VIDEO SERVICES. A QUANTITATIVE AND DESCRIPTIVE STUDY
}

\section{Servicios de vídeo basados en web. Un estudio cuantitativo y descriptivo}

José-Borja Arjona-Martín and Juan-Salvador Victoria-Mas
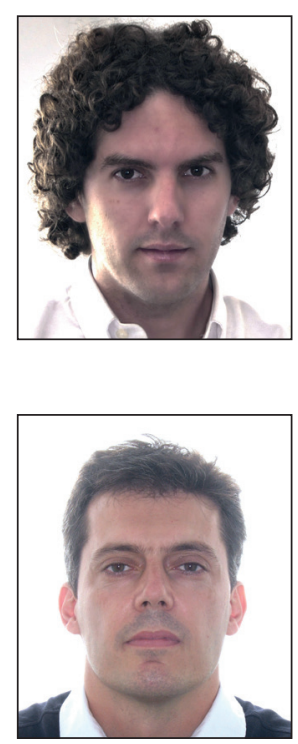

José-Borja Arjona-Martín is professor of Audiovisual Communication at the Communication and Information Area in the University of Granada. He works as a researcher on the projects "Cyberculture, communication process, and audiovisual media (SEJ_508)" and "New advertising forms and new economy (SEJ_396)". His main lines of research are focused on interactive television, Internet video, new forms of production and delivery of audiovisual content, and the video games industry. http://orcid.org/0000-0003-3094-0020

Universidad de Granada, Departamento de Información y Comunicación Campus de Cartuja, 18071 Granada, Spain jbarjona@ugr.es

Juan-Salvador Victoria-Mas is professor of Advertising and Audiovisual Communication at the School of Communications in the University of Málaga. He is the principal researcher for a project about the Andalucian Community: "New advertising forms and new economy (SEJ_396)". He is a visiting professor at the University of Illinois (USA), Northwestern University (USA), Institute of Higher European Studies (Holland), Universidad Bolivariana de Medellín (Colombia), and Universidad Realística de México. He is an advisor for national and international communication companies, including McCann-Ericksson, Grupo Ingenia, Ari Telecom, Dinacom Consulting. He is also the author of six books and more than fifty articles related to audiovisual, commercial, and interactive communication.

http://orcid.org/0000-0002-1818-7438

Universidad de Málaga, Facultad de Ciencias de la Comunicación León Tolstoi, s/n. 29010 Málaga, Spain jsvictoria@uma.es

\begin{abstract}
A quantitative and descriptive analysis of two hundred web-based video services is presented with an aim to shape the characteristics of these new audiovisual media and their relationship with users. The convergence of traditional television features with new media functionalities is determined via a statistical analysis based on observational techniques. Through a statistical analysis we identify the relationships between the established variables and how they shape our sample. Findings reveal that interpersonal communication acquires relevance just as it does in paradigmatic cases, so options for participation are limited in terms of user experience. Functions that allow interpersonal exchange, as well as the user-generated content, were insignificant for our sample. Therefore, according to the data obtained, interactivity is not a quality that defines our study sample. Streaming video and delivery networks are fully consolidated, being the activity of greater growing on the Internet. Currently there are no empirical studies that systematically analyze initiatives regarding the distribution of audiovisual content on the Internet. Audiovisual content is a media that is characterized by the convergence of broadcasters and user-generated content along with the typical features of traditional media and newer network technologies.
\end{abstract}

\section{Keywords}

Web-based video; Interactivity; Traditional media; User experience; Convergence.

\section{Resumen}

Se presenta un análisis cuantitativo y descriptivo de doscientos servicios de vídeo basados en la web con el objetivo de modelar las características de estos nuevos medios audiovisuales y su relación con los usuarios. La convergencia de las características tradicionales de la televisión con las nuevas funciones de los medios se determina mediante un análisis estadístico basado en técnicas de observación. A través de un análisis estadístico se descubren las relaciones entre las variables establecidas y la forma en que moldean la muestra. Los resultados revelan que la comunicación interpersonal adquiere relevancia sólo en casos paradigmáticos, por lo que las opciones de participación son limitadas en términos de experiencia de usuario. Las funciones que permiten opciones para el intercambio interpersonal, así como el contenido generado por el usuario resultó insignificante en nuestra muestra. Por lo tanto, de acuerdo con los datos obtenidos, la interactividad 
no es una cualidad que defina nuestra muestra de estudio. Las redes de streaming y oferta de vídeo ya están bien consolidadas, siendo la actividad de mayor crecimiento en Internet, pero no tenemos estudios empíricos cuyo objetivo principal sea analizar sistemáticamente las iniciativas de distribución de contenidos audiovisuales en Internet. Se trata de un medio caracterizado por la convergencia de las emisoras y el contenido generado por los usuarios, y las características típicas de los medios tradicionales con las nuevas tecnologías de red.

\section{Palabras clave}

Vídeo basado en la web; Interactividad; Medios de comunicación tradicionales; Experiencia de usuario; Convergencia.

Arjona-Martín, José-Borja; Victoria-Mas, Juan-Salvador (2017). “Web-based video services. A quantitative and descriptive study". El profesional de la información, v. 27, n. 1, pp. 75-85.

https://doi.org/10.3145/epi.2018.ene.07

\section{Introduction}

Video streaming and online audiovisual delivery networks have been fully consolidated, a result of the greatest Internet growth to date, with the exception of social networks. Nevertheless, empirical studies have not been conducted that systematically analyze the distribution initiatives of audiovisual content on the Internet. For this reason, our research examines several variables related to the content and functions of audiovisual content in order to identify a relationship between these new audiovisual media and their users.

We suggest streaming video is a media characterized by the convergence of professionally produced videos (broadcasters) and user-generated content, along with a mixture of features from traditional media and new media. In other words, we are discussing a paradigmatic development of interactivity. According to Chung (2007, p. 43)

"the use of interactive features on the Internet has the potential to trigger a paradigm shift in mass media by challenging the traditional unidirectional flow of messages through features that provide bi-directional or even multi-directional communication".

The aim of this paper is not to provide predictions about potential changes in mass media because of interactive features on the internet, instead, we aim to identify the emergence of an embryonic interactive television ecosystem.

\section{The nature of interactive TV}

The convergence of computer and telecommunication technologies has resulted in a new media that combines interactive media communication with social cooperation between users and the production, distribution, and management of content, ultimately resulting in the user's experience. User experience with television has evolved greatly: in the past users simply switched between channels or used analogue teletext in the 1970s (Vinayagamoorthy et al., 2002, p. 589); then, there was the "Red button" which users could press on their remote control to activate interactive television services; and now the current ecosystem where

"users increasingly choose TV devices with IP connectivity and the ability to run web applications. They expect a widening interaction through their connected TV platform" (Vinayagamoorthy et al., 2002, p. 591; Mcdonald, 2007).
In addition, according to Toffler (1980), users are prosumers, meaning they are active figures involved in the production and distribution of audiovisual content.

According to Cesar and Chorianopoulos (2008), from a technological perspective the interactive television defines a

"user experience that involves at least one user and one or more audiovisual and networked devices".

Tsekleves et al. (2009) argued that the technological convergence of television and the Internet defined interactive television during the 90 s. However, due to a plethora of definitions since the 90 s (that included such terms as personalized, enhanced, and connected) it is necessary to continually redefine these emerging services (Carey, 1997). Currently, the concept of the connected television refers to the technological convergence of computers and television sets, in the same way that mobile technologies and computer systems converged to create smartphones (Soursos; Doulamis, 2012). The current environment of television broadcasting is focused on content that is produced specifically for online distribution and applications that deliver content independently from the telecommunication companies (the overthe-top players such as Netflix, Hulu, or Wuaki).

In addition, there is a new approach led by initiatives such as the HbbTV consortium (Hybrid Broadcast Broadband TV), which in 2010 unveiled a standard platform able to deliver content and applications through hybrid systems including digital video broadcasting (DVB) signals and broadband connections. Other projects, like Android TV, combine this operating system and its associated applications in order to develop new hybrid television technology. Philips, Sony, and other manufactures are developing television sets with this operating system based on Android.

In this respect, Kim and Sawhney (2002, p. 224) underlined the paradigmatic

"contradiction between interactivity as a communication form and television as an organizing model".

So already in those years we find a clear definition of interactivity in the current terms. Williams (1974), according to Kim and Sawhney (2002), considered the initiatives launched as reactive TV rather than interactive TV. As opposed to the "machine system", Kim and Sawhney (2002, p. 227) conceived of interactive media as an 
"intelligent system based on the notions of flexibility and contingency".

Previously, Kim and Sawhney (2002, p. 218) described two historical approaches to the concept of interactive TV: (1) a micro perspective, with implications about technology, media, markets, and regulations and the way the interactive communication structures for television are created, and (2) the macro perspective, which tries to conceptualize a "comprehensive domestic communication system" that promotes profound changes, not only in the media landscape, but also in the socio-cultural dimension.

It should not be forgotten that interactivity is also an interpersonal exchange, where messages are the core element of the communication process. Therefore, sharing and exchanging are

"the key elements in interactivity or interactive communication" (Kim; Sawhney, 2002, p. 220).

So interactive media can be a means to recreate an interpersonal-mode of communication-a dialog (Victoria-Mas, 2002; Chung, 2007) within a technological environment.

In this sense, communication deals with

"some elements of user control over narrative content in a media not determined by technology but constituted within culture as a means or desire to co-participate in the text" (Cover, 2006, p. 141).

But, interactivity is also a mediated experience, which emerges from information and communication technology. Accordingly, this approach puts the focus on technological systems that define certain communicative experiences (Steur, 1995).

The current understanding of television has many facets. In media studies, the concept of "technological determinism" is commonly used to describe the power of technology in culture. McQuail (1994; in Burnett; Marshall, 2003) defines "technological determinism" as

"the links between the dominant communication technology of an era and the main characteristics of a society".

We must not forget that the use of technology is also essential for defining media, without necessarily accepting determinism. In this sense, collective intelligence helps to define the form and content of new media as a result of the compilation of individual uses (Malone; Laubacher; Dellarocas, 2009). In addition, interactive communication depends on the level of control users have over the information system (Khan; Vong, 2014); and also, in the "communicational concept" (Victoria-Mas, 2002), on something so little empirical as the intention.

Our hypothesis is that "technological" (more than communicational) interactivity will be present in the main categories and successful elements of our sample. But this presence will be more declarative than effective in the communications our sample elements are going to develop at the level of interpersonal communication.

Based on this hypothesis, the objective of this paper is to define the users' activities within web-based television and video services (in the terms defined by Simpson and Greenfield, 2009) according to a model that examines users' activities conventional and interactive features. The dimensions are related to:

- the transmission modes (one-way, one-to-many, or manyto-many);

- the interpersonal communication and exchange options;

- the responsiveness of the system (platform);

- the circulation of information and ideas; and

- the user's creativity.

It is a model similar to that proposed by Heeter (1989) in the late 80s (applied to a wide range of new media), and Kim and Sawhney (2002) in the early 2000s (specifically for television), as explained in the next section.

\section{Method}

According to the established aim, this paper is a descriptive analysis that uses an observational technique to classify and define the object of the study. Through a statistical analysis we explore the relationships between established variables. In order to shape the study sample, we follow the definition given by Simpson and Greenfield (2009) for Internet video initiatives: web-based video services that use public networks, unmanaged QoS (quality of service), HTTP (hypertext transfer protocol) key protocols, and user experience (which is similar to web surfing over a PC or mobile device).

According to Wimmer and Dominick (2006) in every observational analysis the category system represents the main tool to quantify the variables. We use a binary coding system ( 0 and 1 as possible values) to assign values for every case of our sample, which is formed by two hundred web-based video services (see Annex 2) [Sample updated on October $6,2016]$. In order to compile the sample the snowball sampling technique is used, which is a non-probability technique that uses existing subjects to help recruit other subjects from an unknown universe.

The categories studied (variables) are defined below:

Source: For this category two levels of analysis are defined (Table 1).

Content: This defines the thematic lines of the initiatives that form the sample. This classification shows the general programming goals for each subject. Just in this category the coding system ranges from 1 to 10 (Table 2).

In order to establish the functionalities of the web-based video services in our sample, according to the categories above, some indicators are defined. These indicators represent the computers, web-based environments, and main applications in mass media. They shape the way in which users

Table 1. Subcategories in the source variable

\begin{tabular}{|l|l|c|}
\hline \multicolumn{1}{|c|}{ Subcategory } & \multicolumn{1}{|c|}{ Description } & Code \\
\hline Conventional & $\begin{array}{l}\text { It is an extension of traditional broadcasters } \\
\text { like web-based video services }\end{array}$ & 0 \\
\hline Native & $\begin{array}{l}\text { Those projects created only for their distri- } \\
\text { bution over the web }\end{array}$ & 1 \\
\hline
\end{tabular}


Table 2. Subcategories in the content variable

\begin{tabular}{|c|c|c|}
\hline Subcategory & Description & Code \\
\hline Institutional & $\begin{array}{l}\text { This refers to channels for institutions (public or private) as a means of communication (internal and/ } \\
\text { or external) }\end{array}$ & 1 \\
\hline Business / Corporate & Channels refer to private companies. & 2 \\
\hline Events & Serve as a medium for the coverage of different events & 3 \\
\hline Social & $\begin{array}{l}\text { Interaction system that promotes user-generated content (UGC), interpersonal communication and } \\
\text { information processing }\end{array}$ & 4 \\
\hline General information & Provide all sorts of current information & 5 \\
\hline Specialized information & Provide information about specific topics & 6 \\
\hline General interest & The extension of conventional broadcasters, defined for a general target audience & 7 \\
\hline Local & As the previous one but with regional circumscription & 8 \\
\hline $\begin{array}{l}\text { Entertainment or Varied } \\
\text { content }\end{array}$ & Distribution of varied entertainment videos & 9 \\
\hline Platforms & This refers to television channel aggregators & 10 \\
\hline
\end{tabular}

are able to operate within the system: content organization and ways to access it, interpersonal exchange options and ways to interact with processed information (views, user's evaluation, and opinion about the content). Based on this definition, the binary coding system establishes whether the functionality is included in each subject of our sample ( 0 - it is not included; 1 - it is included).
Kim and Sawhney (2002) defined four core elements present in the interactive TV model:

- communicability (different forms of communication);

- malleability (the use of diverse content or systems);

- programmability (the platform itself serves as a production and processing environment); and

- creativity (user-generated content).

Table 3. Function indicators and their identification number

\begin{tabular}{|c|c|c|}
\hline Functionality indicator & Description & Identification \\
\hline Conventional broadcasting & Definition of timed schedule. & 1 \\
\hline Video upload & Users are allowed to distribute their own video productions. & 2 \\
\hline Video download & Users are allowed to download video onto local hard disk. & 3 \\
\hline Tag clouds & Most searched topics or keywords. Represented as a kind of cell. & 4 \\
\hline Comments & Applications to insert comments on the platform regarding the content. & 5 \\
\hline Referencing via email & It allows users to send web addresses via email. & 6 \\
\hline Evaluation & To rate or vote for the satisfaction level regarding the content. & 7 \\
\hline Content search & Search applications through descriptors or keywords. & 8 \\
\hline Channels & $\begin{array}{l}\text { It allows users to create their own channels within the platform. It is configured as an independent } \\
\text { managing system. }\end{array}$ & 9 \\
\hline Popular rankings & $\begin{array}{l}\text { To collect user information about votes, rates, and viewing data. Content is organized by means of } \\
\text { user's behavior. }\end{array}$ & 10 \\
\hline Sharing & It permits the user to publish and/or refers to content in social networks or via bookmarks. & 11 \\
\hline RSS & RSS subscriptions allow spreading content through adders. & 12 \\
\hline Related contents & Lists with related videos that share keywords with the original one. & 13 \\
\hline Groups & Space for spots for users' association with regard to a common theme. & 14 \\
\hline Chats & Space for spots for real-time conversations (one-to-one, one-to-many, or many-to-many) & 15 \\
\hline Forums & No real-time conversations through a common theme (asynchronous). & 16 \\
\hline Tags & To label video content through keywords. & 17 \\
\hline Embed codes & It allows the insertion of video content on a website from the original source. & 18 \\
\hline Free content & Video freely delivered. & 19 \\
\hline Paid content & Restrictions in content access (pay-per-view or subscriptions). & 20 \\
\hline Live video & Real-time streaming. & 21 \\
\hline Complementary content & To publish other kinds of content that serve as a complement to the video or live streaming. & 22 \\
\hline Advertisement & To deliver ads that work as funding sources. & 23 \\
\hline Theme categories & To classify content under topics (or keywords) or genres. & 24 \\
\hline Links & Redirecting to external websites. These websites may be the information sources or content providers. & 25 \\
\hline
\end{tabular}


Table 4. Function indicators grouped according to the quality of communicability

\begin{tabular}{|l|l|l|}
\hline \multicolumn{1}{|c|}{ Variable/Category } & \multicolumn{1}{|c|}{ Description } & Group of function indicators \\
\hline Unidirectional & $\begin{array}{l}\text { In this variable all the functionalities that define a one-way transmission } \\
\text { mode (close to mass media features) are grouped. }\end{array}$ & $1 ; 3 ; 9 ; 13 ; 21 ; 22 ; 24$ \\
\hline Multidirectional & $\begin{array}{l}\text { Also, this variable collects those capabilities that allow users to exchange and } \\
\text { interact with -and through- the system (user-community and user-system). }\end{array}$ & $2 ; 4 ; 5 ; 6 ; 7 ; 8 ; 10 ; 11 ; 12 ; 14 ; 15 ; 16 ; 17 ; 18 ; 25$ \\
\hline
\end{tabular}

Table 5. Function indicators grouped according to the qualities of malleability, programmability, and creativity

\begin{tabular}{|l|l|l|}
\hline \multicolumn{1}{|c|}{ Variable/Category } & \multicolumn{1}{|c|}{ Description } & \multicolumn{1}{c|}{ Group of function indicators } \\
\hline Spreading & $\begin{array}{l}\text { This allows content spreading throughout external systems (other websi- } \\
\text { tes or social networks). }\end{array}$ & $3 ; 6 ; 11 ; 12 ; 18$ \\
\hline $\begin{array}{l}\text { UGC (user-generated } \\
\text { content) }\end{array}$ & This allows publishing videos and real-time streaming. & $2 ; 9 ; 21$ \\
\hline Evaluation & $\begin{array}{l}\text { This category collects those functionalities that provide information about } \\
\text { users' evaluations (comments and voting), and those tools that set up } \\
\text { rankings from these inputs. }\end{array}$ & $10 ; 24 ; 7 ; 5$ \\
\hline Aggregation & $\begin{array}{l}\text { Virtual spots within websites that serve as vehicles for discussion and } \\
\text { interpersonal communication and exchange. }\end{array}$ & $14 ; 15 ; 16$ \\
\hline $\begin{array}{l}\text { Thematic and genre } \\
\text { classification }\end{array}$ & $\begin{array}{l}\text { Functionalities to locate and classify videos through keywords and themes } \\
\text { or genres. }\end{array}$ & $17 ; 13 ; 8$ \\
\hline
\end{tabular}

Using these elements, we gathered the identified functionalities into different groups. In the first phase, the statistical analysis is based on a multidirectional or conventional communication model (communicability) (Table 4).

In the second statistical analysis, we detailed a classification in terms of malleability (versatility of the medium), programmability (information process to share and exchange) and creativity (a non-professional content creation). All those functionalities that do not fit with the terms defined by Kim and Sawhney are rejected. Every new category is described in Table 5.

Therefore, we used nominal definitions to quantify the frequency of the variables per subject (functionalities) and to classify them within each category. In order to carry out the statistical analysis we used the software SPSS Statistics.

First of all, the distribution of the sample according to the content category was extracted. Then a contingency table was calculated to compare content and source categories. Also, the mean for each functionality indicator was calculated, just to observe the general penetration in the entire sample. After that, an Anova analysis was conducted to compare unidirectional and multidirectional categories with content and source categories. Once weighted average values were calculated for unidirectional and multidirectional dimensions, a T-Test for two related samples was carried out.

Finally, the Anova procedure was also used to determine the relationships between source and content with spreading, UGC, evaluation, aggregation, and thematic and genre classification categories.

\section{Results}

In figure 1 we can observe the distribution of the sample in relation to the variable content. From the 200 web-based video services analyzed, 52 subjects (26\%) were classified as services that specialized in a specific kind of information (for instance politics, economy, health, government, or sports). In second place we found the subcategory entertainment with 48 subjects, $24 \%$ of the sample. Following these two main groups -together they represented $50 \%$ of the sample- we found social and institutional subcategories with 30 (15\%) and 28 (14\%) subjects respectively. Then 19 subjects were classified as general interest and 17 as general information. Finally, we had to consider as marginal subcategories business (1), events (1), locals (3), and platforms (1) sin-

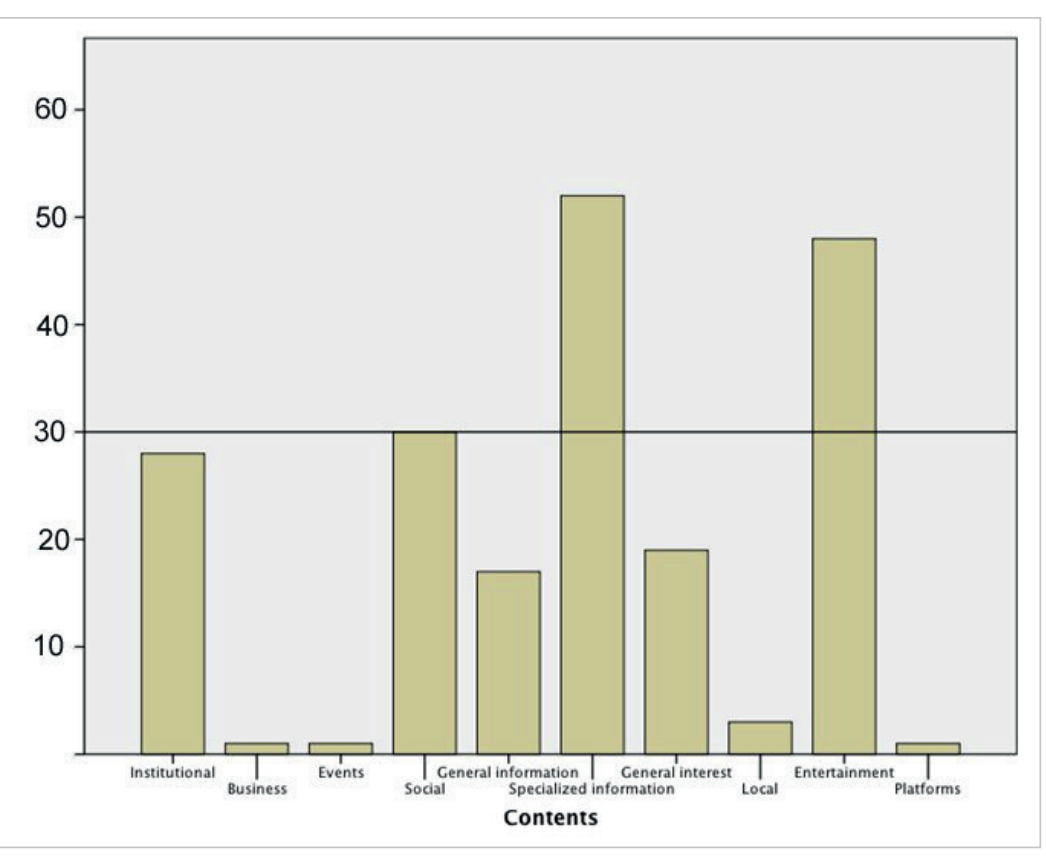

Figure 1. Sample distribution regarding content category 
Table 6. Contingency table between content and source

\begin{tabular}{|c|c|c|c|c|}
\hline & & \multirow{2}{*}{\multicolumn{2}{|c|}{ Source }} & \multirow{3}{*}{ Total } \\
\hline & & & & \\
\hline & & Conventional & Native & \\
\hline \multirow{10}{*}{ Content } & Institutional & 3 & 25 & 28 \\
\hline & Business & 0 & 1 & 1 \\
\hline & Events & 0 & 1 & 1 \\
\hline & Social & 0 & 30 & 30 \\
\hline & General information & 6 & 11 & 17 \\
\hline & Specialized information & 4 & 48 & 52 \\
\hline & General interest & 19 & 0 & 19 \\
\hline & Local & 3 & 0 & 3 \\
\hline & Entertainment & 11 & 37 & 48 \\
\hline & Platforms & 0 & 1 & 1 \\
\hline \multicolumn{2}{|l|}{ Total } & 46 & 154 & 200 \\
\hline
\end{tabular}

Contingency coefficient: 0.566; Sig.: 0.000 Phi: 0.686; Sig.: 0.000

ce they represented just $2.5 \%$ in sum. Virtually they do not have a significant weight in the data obtained.

A contingency table was extracted to compare the correspondence between content and source variables (see Table 6). When we observed the total results, we realized that 154 subjects classified as native were registered, i.e., $77 \%$ of the sample. But we had to consider that the general interest (19) subcategory of content could only admit subjects to a conventional source since it was an extension of traditional broadcasters on the Internet. So if we omitted this subcategory in the analysis, the percentage of native web-based video services increased to $85 \%$. The entertainment subcategory alone obtained a significant number of subjects (11) that belonged to a conventional source. Mainly, this data signified the presence of thematic broadcasters such as $\mathrm{CO}$ medy Central (USA), Mundo Max (USA), or Eurosport Player (EU), and other traditional televisions devoted entirely to general entertaining content like 6Play (France), Televeo (Mex), or Kylin (China), for example.

\section{Apart from the free content indicator,} the most important functionalities within the sample were content search, sharing options and categories

As it was observed that there were no conventional subjects in the social subcategory, it registered just native initiatives (30). Also, the specialized information and institutional categories almost obtained a hundred per cent of native subjects ( 48 subjects, $92 \%$; 25 subjects, $89 \%$, respectively). It is important to underline that the result of this comparison was statistically significant (contingency coefficient: 0.566; Sig.: 0.000 Phi: 0.686; Sig.: 0.000)[Significance level <0.05].

With regard to function indicators, first of all, it was interesting to calculate mean values per each one of them concerning the entire sample. Thereby, we could make an individualized approach to this concept.

According to the data results, $97 \%$ of the sample offered
Table 7. Function indicators mean

\begin{tabular}{|c|c|c|}
\hline & $\mathbf{N}$ & Mean \\
\hline Conventional broadcasting & 200 & 0.25 \\
\hline Video upload & 200 & 0.15 \\
\hline Video download & 200 & 0.11 \\
\hline Tags cloud & 200 & 0.08 \\
\hline Referencing via email & 200 & 0.48 \\
\hline Comments & 200 & 0.49 \\
\hline Evaluation & 200 & 0.47 \\
\hline Content search & 200 & 0.85 \\
\hline Channels & 200 & 0.21 \\
\hline Popular rankings & 200 & 0.27 \\
\hline Sharing options & 200 & 0.82 \\
\hline RSS & 200 & 0.27 \\
\hline Related content & 200 & 0.61 \\
\hline Links & 200 & 0.32 \\
\hline Free content & 200 & 0.97 \\
\hline Paid content & 200 & 0.16 \\
\hline Live video & 200 & 0.35 \\
\hline Advertisement & 200 & 0.63 \\
\hline Categories & 200 & 0.86 \\
\hline Groups & 200 & 0.03 \\
\hline Chats & 200 & 0.06 \\
\hline Forums & 200 & 0.03 \\
\hline Tags & 200 & 0.42 \\
\hline Embedding codes & 200 & 0.54 \\
\hline Complementary content & 200 & 0.44 \\
\hline $\mathrm{N}$ & 200 & \\
\hline
\end{tabular}

free content and just $16 \%$ included paid-content (usually through pay per view or/and subscription formulas). The latter was generally represented by initiatives like Netflix, Wuaki, Hulu or others from conventional broadcasters such as A\&E, CBS, NFB (Canada), or Atresplayer and MiTele, from the Spanish media groups Atresmedia and Mediaset, respectively. Notice that none of the function indicators were mutually exclusive, so one case could include free and paid content. In fact, there were many cases that exemplified the combination of free and paid content (premium, generally); most of which were native: YouTube, Classical TV, Play TV, Streamit or Vimeo, among others.

Apart from the free content indicator, the most important functionalities within the sample were content search (0.85), sharing options (0.82) and categories (0.86). The rest of the functionalities were more or less equally distributed: advertisement (0.63), related content (0.61), embedding codes (0.54), comments (0.49), referencing via email (0.48), complementary content $(0.44)$, tags $(0.42)$, live video $(0.35)$, and links (0.32) were the most representative indicators.

On the flipside, indicators such as groups (0.03), forums (0.03), chats (0.06), tag clouds (0.08) or video downloads (0.11) recorded a really low mean value. Even video uploads, which represented the most relevant feature of 
Table 8. Anova procedure comparing unidirectional, multidirectional, and content variables

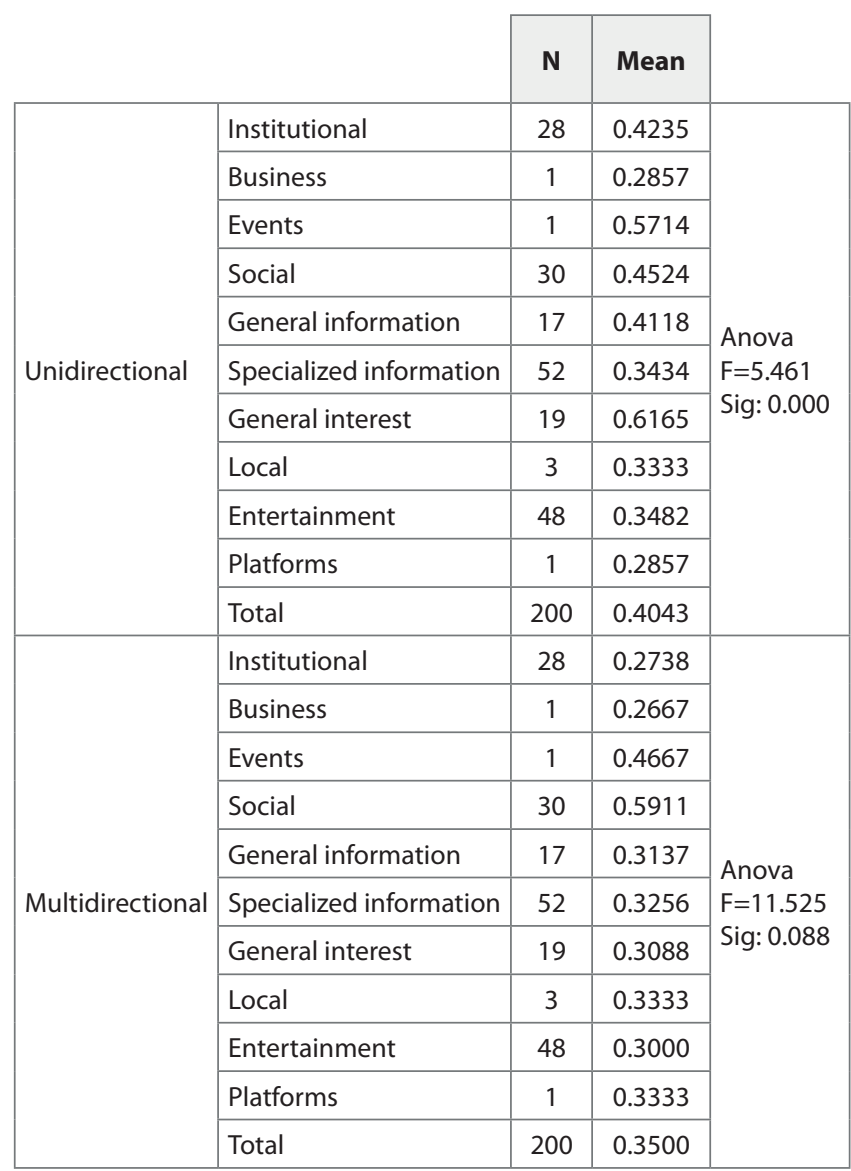

the user-generated content category recorded one of the lowest means (0.15). The functionalities mentioned above (groups, forums, and chats), that were considered as digital spaces for interpersonal communication (one-to-one, oneto-many, or many-to-many) were irrelevant for the analyzed sample. So, the sample was actually defined by the options that related to the content with the platform and the users. Most of these functionalities were aimed at optimizing the content access (theme categories, list of related videos, and tags which served to label and improve searching) or to spread videos through other websites or social networks (sharing and embedding).

In terms of communication models, we conducted an Anova to extract significant relationships among content, unidirectional, and multidirectional categories (see Table 8). In global terms, unidirectional functions recorded a mean of 0.4043 , i.e., $40 \%$ of the sample setup functionalities that belonged

Table 9. Anova procedure comparing unidirectional and source variables

\begin{tabular}{|l|c|c|}
\hline \multicolumn{3}{|c|}{ Unidirectional } \\
\hline \multicolumn{1}{|c|}{ Source } & Mean & N \\
\hline Conventional & 0.5248 & 46 \\
\hline Native & 0.3683 & 154 \\
\hline Total & 0.4043 & 200 \\
\hline
\end{tabular}

Anova $\mathrm{F}=30.121 \mathrm{Sig}: 0.000$

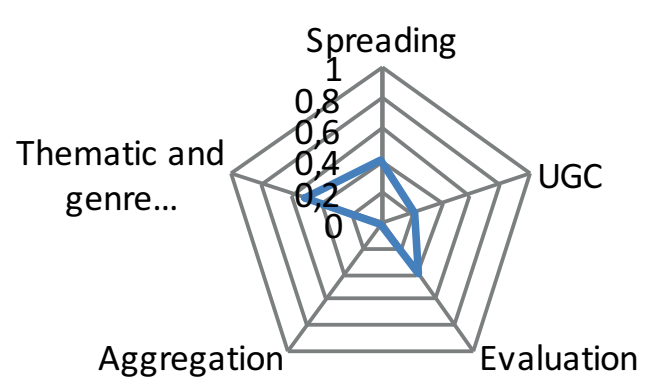

Institutional

Figure 2. Institutional weighted mean values

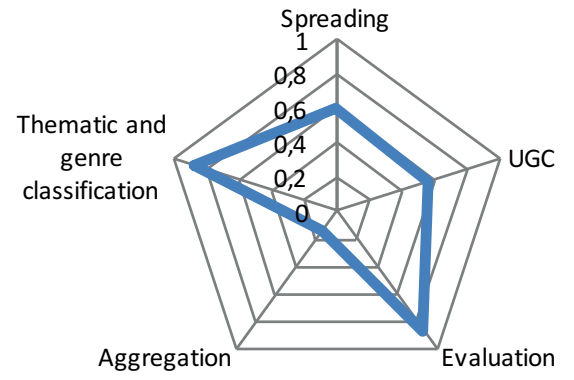

Social

Figure 3. Social weighted mean values

to traditional communication models. However, the multidirectional variable or group reached a mean of 0.35 , which signified that $35 \%$ of the sample incorporated functionalities that encouraged the interactive nature of electronic and connected media. Nevertheless, the relationships established in the multidirectional field were not statistically significant ( $F=11.525$ Sig: 0.088) unlike the unidirectional field, which actually was statistically significant ( $F=5.461 \mathrm{Sig}$ : 0.000).

We observed general interest has a conventional orientation with the highest mean of any subcategory in the unidirectional variable (0.6165), while it obtained just a 0.3088 mean to multidirectional functionalities (mean diff.=0.3077).

On the contrary, social subjects added up to almost $60 \%$ of multidirectional functionalities, a difference of 0.1387 points regarding unidirectional options (mean value $=0.4524$ ). So, a logical definition (based on the nature of the subjects) was established about both content subcategories (Table 9).

Table 10. Anova procedure comparing multidirectional and source variables

\begin{tabular}{|l|c|c|}
\hline \multicolumn{3}{|c|}{ Multidirectional } \\
\hline \multicolumn{1}{|c|}{ Source } & Mean & N \\
\hline Conventional & 0.2826 & 46 \\
\hline Native & 0.3701 & 154 \\
\hline Total & 0.3500 & 200 \\
\hline
\end{tabular}

Anova $F=9,309$ Sig: 0.003 


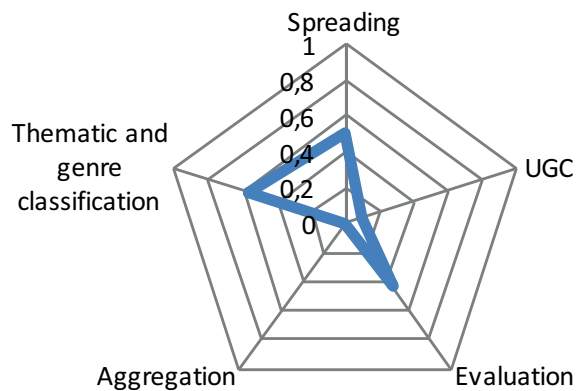

General information

Figure 4. General information weighted mean values

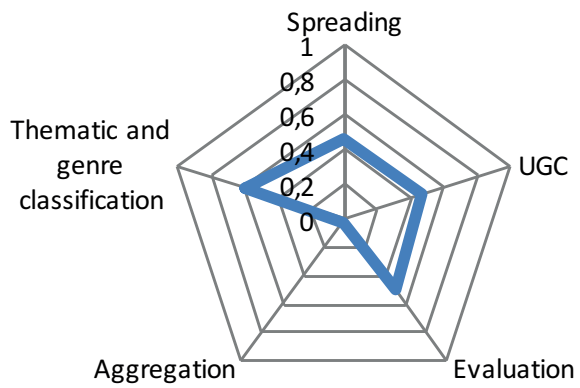

General interest

Figure 6. General interest weighted mean values

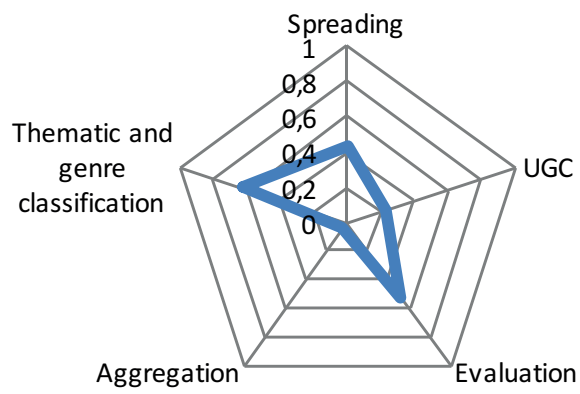

Total

Figure 8. Total weighted mean values

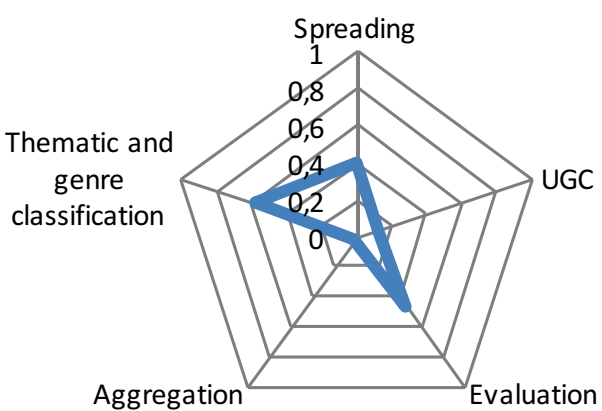

Specialised information

Figure 5. Specialised information weighted mean values

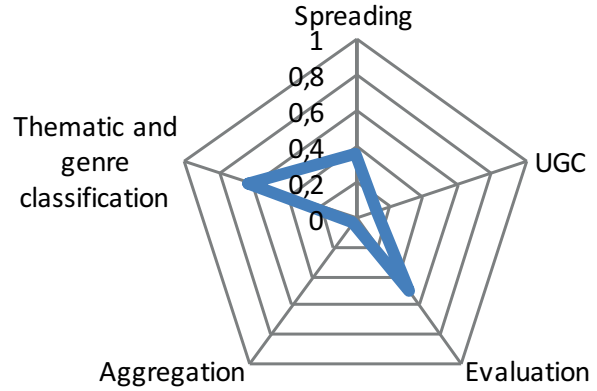

Entertainment

Figure 7. Entertainment weighted mean values

But also, institutional, a purely native subcategory, registered an important mean difference in favor of unidirectional functionalities (mean diff.=0.1497). The rest of the content subcategories with enough representation in the sample also had a mean difference value in favor of unidirectional variable: general information (mean diff. $=0.0981$ ), specialized information (mean diff. $=0.0178$ ), and entertainment (mean diff. $=0.0482$ ). Thus, according to the data obtained, in the sample under study a conventional (mass media) communication model prevailed, even though the mean difference value with regard to multidirectional functionalities

Table 11. Statistics from a T-test analysis for unidirectional and multidirectional variables

\begin{tabular}{|l|c|c|c|c|}
\hline & Mean & $\mathbf{N}$ & Std. deviation & Std. error mean \\
\hline Unidirectional & 0.4043 & 200 & 0.18178 & 0.01285 \\
\hline Multidirectional & 0.3500 & 200 & 0.17425 & 0.01232 \\
\hline
\end{tabular}

Table 12. Significance value from the T-test procedure

\begin{tabular}{|c|c|c|c|c|c|c|c|c|}
\hline & \multicolumn{5}{|c|}{ Paired differences } & \multirow{3}{*}{$\mathrm{t}$} & \multirow{3}{*}{ df } & \multirow{3}{*}{$\begin{array}{l}\text { Sig. } \\
\text { (2-tailed) }\end{array}$} \\
\hline & \multirow[t]{2}{*}{ Mean } & \multirow{2}{*}{$\begin{array}{l}\text { Std. devia- } \\
\text { tion }\end{array}$} & \multirow{2}{*}{$\begin{array}{l}\text { Std. error } \\
\text { mean }\end{array}$} & \multicolumn{2}{|c|}{$\begin{array}{l}95 \% \text { confidence interval } \\
\text { of the difference }\end{array}$} & & & \\
\hline & & & & Lower & Upper & & & \\
\hline $\begin{array}{l}\text { Unidirectional- } \\
\text { Multidirectional }\end{array}$ & 0.05429 & 0.23130 & 0.01636 & 0.02203 & 0.08654 & 3.319 & 199 & 0.001 \\
\hline
\end{tabular}


was just 0.0543 . Therefore, considering the previous observation, we found almost a balanced situation between both unidirectional and multidirectional variables.

Additionally, a comparison of weighted means in these two variables was calculated according to the source variable (see Tables 9 and 10). With regard to unidirectional functionalities, the data obtained from the analysis confirmed that conventional subjects achieved the highest value for this kind of functionality $(M=0.5248)$. Unlike native subjects, which registered a mean of 0.3683 , the difference was 0.1565 points between both variables. These relationships among variables turned out to be statistically significant $(F=30.121$, sig. $=0.000)$. As it was expected, native web-based video platforms had a superior weighted mean for multidirectional indicators $(M=0.3701)$, however, a smaller difference between means (mean diff. $=0.0875$ ) was recorded.

To conclude, with the first analysis a T-Test was conducted (see Tables 11 and 12) for two related samples in order to compare unidirectional and multidirectional variables (extracted by adding-up function indicators). This test served to confirm that the difference between both variables was statistically significant (means diff.=0.05429; $\mathrm{t}=3.319$, sig. $=0.001$ ).

Regarding the second phase, it was statistically confirmed (see Table 13) that the social subcategory had the highest mean in every category (Spreading $\mathrm{M}=0.6067$; UGC $\mathrm{M}=0.5667$; Evaluation $\mathrm{M}=0.8667$; Aggregation $\mathrm{M}=0.1444$ and Thematic and genre classification $\mathrm{M}=0.8778$ ). Figure 3 illustrates the importance of this content subcategory, mostly in the Evaluation and Thematic and genre classification, as happened in the entire sample, in which the abovementioned categories and Spreading are the most representative features of the sample (see Table 13 and Figure 8).

Also, entertainment and general interest subcategories got a high mean in UGC (General interest $M=0.4561$ ), Evaluation (Entertainment $\mathrm{M}=0.5$; General interest $\mathrm{M}=0.4868$ ) and Thematic and genre classification (Entertainment $M=0.6250$; General interest $M=0.5965$ ).

It is striking that a purely conventional subcategory such as general interest obtained high values in user-generated content indicators, but it was mostly due to the channels indicator, which serves to create and manage individual channels within the global website. In the social sub-category, independent users managed the majority of these channels, but the general interest subcategory included the broadcasters who handled the channels. So, it is a contradiction because the channels indicator was not representing users' content for the general interest subcategory.

When these categories were compared with the source variable the results were statistically significant for UGC ( $\mathrm{F}=7.070$; Sig.=0.008) and Evaluation ( $\mathrm{F}=8.256$; Sig.=0.005), in which the conventional subcategory gets the highest mean ( $M=0.3333)$ for the UGC cate-
Table 13. Anova procedure comparing spreading, UGC, evaluation, aggregation and thematic with content variables

\begin{tabular}{|c|c|c|c|c|c|}
\hline & & & & \\
\hline & & $\mathbf{N}$ & Mean & $\mathbf{F}$ & Sig. \\
\hline \multirow{11}{*}{ Spreading } & Institutional & 28 & 0.4000 & \multirow{11}{*}{3.124} & \multirow{11}{*}{0.002} \\
\hline & Business & 1 & 0.6000 & & \\
\hline & Events & 1 & 0.8000 & & \\
\hline & Social & 30 & 0.6067 & & \\
\hline & General information & 17 & 0.5059 & & \\
\hline & Specialized information & 52 & 0.4077 & & \\
\hline & General interest & 19 & 0.4526 & & \\
\hline & Local & 3 & 0.4667 & & \\
\hline & Entertainment & 48 & 0.3583 & & \\
\hline & Platforms & 1 & 0.4000 & & \\
\hline & Total & 200 & 0.4410 & & \\
\hline \multirow{11}{*}{ UGC } & Institutional & 28 & 0.2262 & \multirow{11}{*}{13.576} & \multirow{11}{*}{0.000} \\
\hline & Business & 1 & 0.0000 & & \\
\hline & Events & 1 & 0.0000 & & \\
\hline & Social & 30 & 0.5667 & & \\
\hline & General information & 17 & 0.0980 & & \\
\hline & Specialized information & 52 & 0.1218 & & \\
\hline & General interest & 19 & 0.4561 & & \\
\hline & Local & 3 & 0.3333 & & \\
\hline & Entertainment & 48 & 0.1250 & & \\
\hline & Platforms & 1 & 0.6667 & & \\
\hline & Total & 200 & 0.2383 & & \\
\hline \multirow{11}{*}{ Evaluation } & Institutional & 28 & 0.4018 & \multirow{11}{*}{8.279} & \multirow{11}{*}{0.000} \\
\hline & Business & 1 & 0.2500 & & \\
\hline & Events & 1 & 0.7500 & & \\
\hline & Social & 30 & 0.8667 & & \\
\hline & General information & 17 & 0.4412 & & \\
\hline & Specialized information & 52 & 0.4567 & & \\
\hline & General interest & 19 & 0.4868 & & \\
\hline & Local & 3 & 0.5000 & & \\
\hline & Entertainment & 48 & 0.5000 & & \\
\hline & Platforms & 1 & 0.2500 & & \\
\hline & Total & 200 & 0.5225 & & \\
\hline \multirow{11}{*}{ Aggregation } & Institutional & 28 & 0.0000 & \multirow{11}{*}{3.263} & \multirow{11}{*}{0.001} \\
\hline & Business & 1 & 0.0000 & & \\
\hline & Events & 1 & 0.0000 & & \\
\hline & Social & 30 & 0.1444 & & \\
\hline & General information & 17 & 0.0000 & & \\
\hline & Specialized information & 52 & 0.0192 & & \\
\hline & General interest & 19 & 0.0175 & & \\
\hline & Local & 3 & 0.0000 & & \\
\hline & Entertainment & 48 & 0.0347 & & \\
\hline & Platforms & 1 & 0.0000 & & \\
\hline & Total & 200 & 0.0367 & & \\
\hline \multirow{11}{*}{ Thematic } & Institutional & 28 & 0.5238 & \multirow{11}{*}{20.897} & \multirow{11}{*}{0.003} \\
\hline & Business & 1 & 0.3333 & & \\
\hline & Events & 1 & 1.0000 & & \\
\hline & Social & 30 & 0.8778 & & \\
\hline & General information & 17 & 0.5686 & & \\
\hline & Specialized information & 52 & 0.5833 & & \\
\hline & General interest & 19 & 0.5965 & & \\
\hline & Local & 3 & 0.5556 & & \\
\hline & Entertainment & 48 & 0.6250 & & \\
\hline & Platforms & 1 & 0.3333 & & \\
\hline & Total & 200 & 0.6283 & & \\
\hline
\end{tabular}


Table 14. Anova procedure comparing spreading, UGC, evaluation, aggregation and thematic with source variables

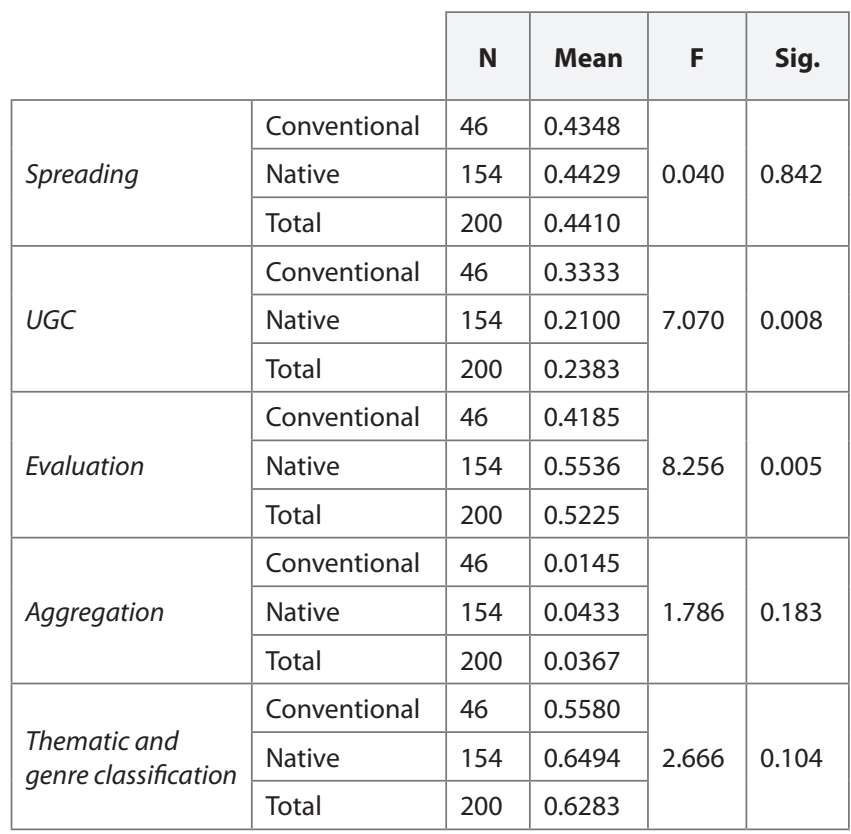

gory, because of the reason explained before, and the native subcategory registered the highest mean $(M=0.5536)$ in the Evaluation category.

Interestingly, the differences between conventional and native were not statistically significant for Spreading, Aggregation, and Thematic and genre classification categories, in which the native subcategory obtained the highest mean in the three categories $(M=0.4429 ; M=0.0433 ; M=0.6494$, respectively).

The social subcategory had the highest mean in every category mostly in the Evaluation and Thematic and genre classification, as happened in the entire sample, in which these two categories and Spreading are the most representative features

\section{Conclusions}

In regards to our hypothesis, we can say that web-based video services have achieved an effective way to interact with audiovisual content through connected and electronic media and devices.

However, we found in our sample that interpersonal communication and interaction with social networks was relevant within limited spaces (the social subcategory) and the participation options were simplified in terms of user experience. Functionalities such as groups, forums, or chats, which allow a space for interpersonal exchange, were insignificant for our sample. Thus, the user's influence was limited to simple and immediate actions (comments or votes).

On the other hand, user-generated content was restricted to paradigmatic subjects (such as YouTube or Vimeo),

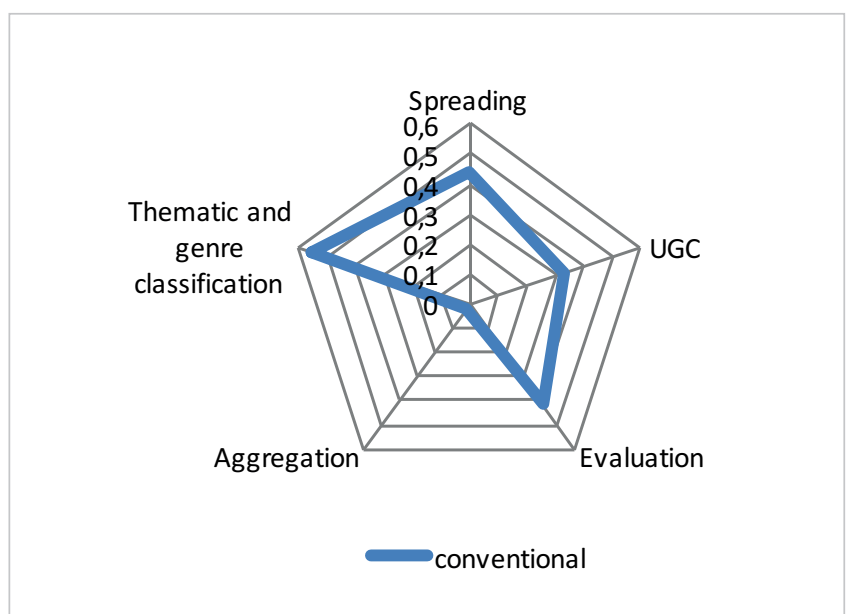

Figure 9. Conventional weighted mean values

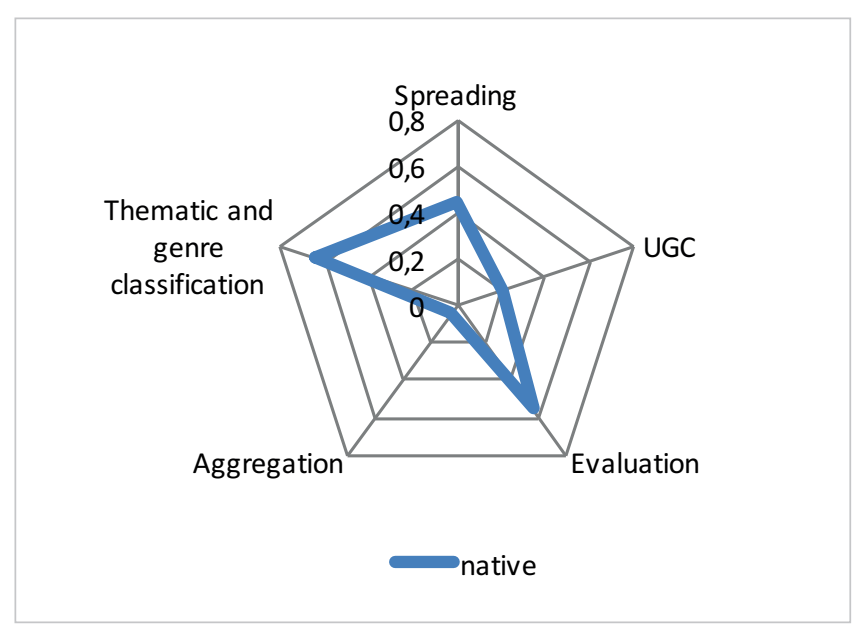

Figura 10. Native weighted mean values

so the collection of data about content usage, rather than the production and sharing of original content, defined user participation. This was confirmed by observing the weighted mean registered by Evaluation and Thematic and genre classification categories ( $M=0.5225$ and $M=0.6250$, respectively), which gather functionalities to label, search, and classify content through genre, thematic topics, or popularity (rankings) and other options or tools that used qualitative information (comments) and average valuations based on numeric scales (votes) in order to organize the content. So, a way to interact with web-based video platforms that shapes the structures of how content is valued by the system was established. But just a small percentage of the subjects allowed users to really participate in exchanges with others in a synchronous or asynchronous way.

It is striking that a purely conventional subcategory such as general interest obtained high values in user-generated content indicators

According to the data obtained, the content subcategories business, events, local, and platforms were not significant in the study sample. This was probably due to the snowba- 
II sampling technique, which made it hard to collect other subjects that could be classified according to the established definitions for every content subcategory. Nevertheless, in a framework determined by a strong economic crisis, the chance of an inflation that leads to the disappearance of multiples and relevant initiatives that were encouraged by online communication promises also exists. So, we found a model influenced by conventional structures of television rather than by the native and interactive formulas set up by electronic and networked systems.

Finally, a comparative analysis between the users registered in every website and its level of interactive functionalities as well as the effective use of the diverse indicators may guide further academic research on new media and interactivity.

Web-based video services have achieved an effective way to interact with audiovisual content through connected and electronic media and devices

\section{References}

Burnett, Robert; Marshall, David (2003). Web theory. An introduction. London, UK: Routledge. ISBN: 9780415238342

Carey, John (1997). "Interactive television trials and marketplace experiences". Multimedia tools and applications, v. 5, n. 2, pp. 207-216.

https://goo.gl/CfTz6L

https://doi.org/10.1023/A:1009649402461

César, Pablo; Chorianopoulos, Konstantinos (2008). "Interactivity and user participation in the television lifecycle: Creating, sharing, and controlling content". In: Proceedings of the $1^{\text {st }}$ Intl conf on designing interactive user experiences for TV and video, New York, pp. 125-128. ISBN: 9781605581002 https://goo.gl/QfZ8os

Chung, Deborah-Soun (2007). "Profits and perils. Online news producers' perceptions of interactivity and uses of interactive features". Convergence: The international journal of research into new media technologies, v. 13, n. 1, pp. 43-61. https://goo.gl/MGLbkF https://doi.org/10.1177/1354856507072856

Cover, Rob (2006). "Audience interactive: Interactive media, narrative control and reconceiving audience history". New media \& society, v. 8, n. 1, pp. 139-158.

https://goo.gl/UUL9GY

https://doi.org/10.1177/1461444806059922

Heeter, Carrie (1989). "Implications of new interactive technologies for conceptualizing communication”. In: Salvaggio, Jerry L.; Bryant, Jennings (eds). Media use in the information age, pp. 217-235. Hillsdale, NJ: Lawrence Erlbaum Associates. ISBN: 9780898599688

https://goo.gl/97bEas

Khan, Gohar-Feroz; Vong, Sokha (2014). "Virality over YouTube: An empirical analysis". Internet research, v. 24, n. 5, pp. 629-647.

https://goo.gl/fBkYBd

https://doi.org/10.1108/IntR-05-2013-0085
Kim, Pyungho; Sawhney, Harmeet (2002). "A machine-like new medium - Theoretical examination of interactive TV". Media, culture and society, v. 24, n. 2, pp. 217.

https://goo.gl/efpmmc

https://doi.org/10.1177/016344370202400204

Macdonald, Myra (2007). "Television debate, 'interactivity' and public opinion: The case of the BBC's 'Asylum day'". Media, culture and society, v. 29, n. 4, 679-689.

https://goo.gl/4jpw7h

https://doi.org/10.1177/0163443707078429

Malone, Thomas W.; Laubacher, Robert; Dellarocas, Chrysanthos (2009). Harnessing crowds: Mapping the genome of collective intelligence. Working paper n. 2009-001. MIT Center for Collective Intelligence. Cambridge, MA: Massachusetts Institute of Technology.

http://cci.mit.edu/publications/CClwp2009-01.pdf

Simpson, Wes; Greenfield, Howard (2009). IPTV and internet video: Expanding the reach of television broadcasting. Burlington, Massachusetts: Focal Press. https://doi.org/10.1016/B978-0-240-81245-8.00018-9

Soursos, Sergio; Doulamis, Nikos (2012). “Connected TV and beyond". Consumer communications and networking conference (CCNC).

https://doi.org/10.1109/CCNC.2012.6181009

Steur, Jonathan (1995). "Defining virtual reality: Dimensions determining telepresence". In: Biocca, Frank; Levy, Mark (eds.). Communication in the age of virtual reality. Hillsdale, NJ: LEA, pp. 33-56. ISBN: 9780805815504

Toffler, Alvin (1980). The third wave. New York: William Morrow. https://archive.org/stream/TheThirdWave-Toffler/TheThird-Wave - Toffler djvu.txt

https://es.scribd.com/document/2911053/Toffler-Alvin-Latercera-ola

Tsekleves, Emmanuel; Cosmas, John; Aggoun, Amar; Loo, Jonathan (2009). "Converged digital TV services: The role of middleware and future directions of interactive television". International journal of digital multimedia broadcasting. ID 643680, 19 pp.

https://doi.org/10.1155/2009/643680

Vinayagamoorthy, Vinoba; Allen, Penelope; Hammond, Matt; Evans, Michael (2002). "Researching the user experience for connected TV. A case study". In: CHI '12 Extended abstracts on human factors in computing systems, May 5-10, pp. 589-604 https://doi.org/10.1145/2212776.2212832

Victoria-Mas, Juan-Salvador (2002). “Diálogo e interactividad en la comunicación comercial". Razón y palabra, n. 27, June-July. http://www.razonypalabra.org.mx/anteriores/n27/jvictoria. html\#jv

Williams, Raymond (1974). Television: Technology and cultural form. Hanover, NH: Wesleyan University Press. ISBN: 0 203426649

Wimmer, Roger; Dominick, Joseph (2006). Mass media research: An introduction. Belmont: Thomson Wadsworth. ISBN: 9781439082744 